\title{
Procedimentos Terapêuticos de Enfermagem no Contexto da Dor: a Percepção de Pacientes
}

\author{
Silveira, Rosemary Silva da; Silveira, Nara Beatriz; Lunardi, Valéria Lerch; Fernandes, \\ Geani Farias Machado; Saioron, Isabela; Gonçalves, Naiane Glaciele da C.
}

Universidade Federal do Rio Grande - anacarol@mikrus.com.br

Introdução: a dor interfere diretamente no estado físico e psicossocial dos indivíduos, prejudicando sua qualidade de vida. Constitui-se numa das principais causas de sofrimento dos pacientes, e no motivo do grande número de internações hospitalares, estando ligada intimamente ao cuidado, o que requer ser avaliada de forma minuciosa em suas diferentes dimensões pelos trabalhadores de enfermagem. Objetivou-se conhecer a percepção dos pacientes acerca dos procedimentos terapêuticos utilizados pelos trabalhadores da enfermagem para o alívio da dor. Metodologia: tratase de uma pesquisa qualitativa. para a coleta de dados obteve-se a aprovação do Comitê de Ética em Pesquisa na Área da Saúde e utilizou-se a técnica de entrevista semi estruturada. Participaram do estudo trinta e oito pacientes internados em um Hospital Universitário do extremo Sul do Brasil. o processo de análise dos dados foi realizado através da técnica de Análise Textual Discursiva, composta de quatro focos: desmontagem dos textos, estabelecimento de relações, captando o novo emergente e um processo auto organizado. Resultados: Emergiram três categorias: o significado e a limitação da dor expresso pelos pacientes, procedimentos terapêuticos praticados pela equipe de enfermagem para aliviar a dor e a utilização de instrumentos para avaliação da dor. ao buscar evidenciar o significado da experiência de dor no discurso dos pacientes, foi possível constatar que os pacientes compreendem a dor como uma dimensão total, que ultrapassa o limite de uma condição física de doença, estendendo-se para as dimensões psicológicas e sociais. Os sujeitos relacionam ainda a experiência de dor com sofrimento, impotência, sensação de mal estar, principalmente, quando associada a um diagnóstico indefinido, que pode produzir medo de uma incapacidade permanente, da morte, de não poder sustentar a família, ocasionando incertezas e desejos de suicídio. uma minoria dos pacientes referiu que além da medicação, os trabalhadores costumam realizar outros procedimentos terapêuticos para aliviar sua dor, como massagens, aplicação de óleos, de compressas, de bolsas de calor e frio. no que se refere à utilização de métodos para avaliação da intensidade da dor, a maioria dos entrevistados relatou não existir avaliação por parte da equipe de enfermagem. em poucos discursos, é referido o uso de investigação em forma de perguntas quanto à intensidade da dor e sua localização. Conclusões: Considera-se necessário implementar a utilização de escalas para avaliação da dor e de protocolos para sistematizar as ações da enfermagem. a não-existência de protocolo de avaliação da dor na instituição pode dificultar uma assistência direcionada e individualizada ao paciente com dor. Compreende-se que é necessário envolver a participação de outros trabalhadores, não só da enfermagem, mas da equipe multiprofissional, pois a dor envolve a todos, inclusive os familiares.

Silveira, Rosemary Silva da; Silveira, Nara Beatriz; Lunardi, Valéria Lerch; Fernandes, Geani Farias Machado; Saioron, Isabela; Gonçalves, Naiane Glaciele da C.. Procedimentos Terapêuticos de Enfermagem no Contexto da Dor: a Percepção de Pacientes. In: Anais do Congresso Internacional de Humanidades \& Humanização em Saúde [= Blucher Medical Proceedings, num.2, vol.1]. São Paulo: Editora Blucher, 2014. ISSN 2357-7282

DOI 10.5151/medpro-cihhs-10687 